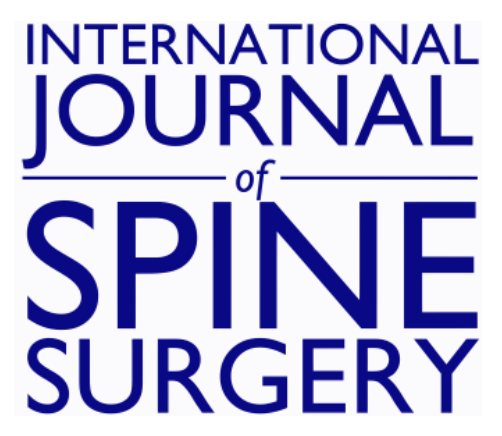

\title{
A Rare Entity in the Lumbar Epidural Region: T-Cell Lymphoblastic Lymphoma
}

Münibe Büsra Erdem, Aydemir Kale, Mesut Emre Yaman and Hakan Emmez

Int J Spine Surg 2021, 14 (s4) S52-S56

doi: https://doi.org/10.14444/7165

http://ijssurgery.com/content/14/s4/S52

This information is current as of April 26, 2023.

Email Alerts Receive free email-alerts when new articles cite this article. Sign up at:

http://ijssurgery.com/alerts 


\title{
A Rare Entity in the Lumbar Epidural Region: T-Cell Lymphoblastic Lymphoma
}

\author{
MÜNIBE BÜŞRA ERDEM, MD, AYDEMIR KALE, MD, MESUT EMRE YAMAN, MD, HAKAN EMMEZ, \\ MD \\ Department of Neurosurgery, Gazi University Faculty of Medicine, Ankara, Turkey
}

\begin{abstract}
Background: T-cell lymphoblastic lymphoma is a rare disease and an aggressive neoplasm of precursor lymphoblasts. We present a case of lumbar epidural T-cell lymphoblastic lymphoma which appeared with clinical features of epidural spinal cord compression.

Methods: A 38-year-old male patient presented with weakness in the lower extremities and newly developed urinary incontinence. His medical history included precursor T-cell acute lymphoblastic leukemia and treatment with allogeneic bone-marrow transplantation 5 years previously. Spinal magnetic resonance imaging (MRI) revealed an epidural mass lesion at L2-L4 levels and there was no sign of leukemia or lymphoma in clinical, laboratory, and radiological examinations. Surgery was planned for obtaining diagnostic material. Decompressive laminectomy and subtotal excision of the tumor were performed.

Results: At surgery, the tumor consisted of yellow-colored and hypovascular soft tissue fragments. It was encircling the spinal cord and spreading through the left L3 foramen. The patient underwent adjuvant chemoradiotherapy after the histopathological evaluation. At 2-month follow-up, the patient was able to walk without assistance, but the urinary incontinence was the same. At 5-month follow-up, the disease progressed, and the patient passed away because of infective endocarditis.

Conclusion: Spinal lymphomas may display its characteristic "wrap-around" fashion in the MRI. In this report, we shared the microsurgical appearance of this fashion. As the lymphomas are chemoradiosensitive tumors, the treatment should be managed with a multidisciplinary approach.
\end{abstract}

Tumors

Keywords: epidural space, spinal cord compression, precursor T-cell lymphoblastic leukemia-lymphoma, recurrence, tumor

\section{INTRODUCTION}

Spinal lymphoma is a relatively uncommon tumor and accounts for $10 \%$ of spinal epidural tumors. ${ }^{1}$ Non-Hodgkin lymphoma comprises $85 \%$ of the cases. ${ }^{2}$ Spinal involvement may be seen as the initial finding or during the course of the disease. ${ }^{3}$ Lymphoblastic lymphoma (LBL) is a rare disease, comprising only $2 \%$ of non-Hodgkin lymphomas. ${ }^{4}$ T-cell LBL (T-LBL) accounts for 90\% cases of LBL and occurs predominantly in children and adolescents. ${ }^{5}$ Central nervous system (CNS) involvement is uncommon at presentation $(3 \%-9 \%)$ in T-LBL. ${ }^{6}$ Nonetheless, CNS is often the first site of relapse. ${ }^{6}$ In this report, we present a recurrent $\mathrm{T}$-cell acute lymphoblastic leukemia (T-ALL)/T-LBL with the clinical findings of epidural spinal cord compression. Our aim is to demonstrate this rare entity with its microsurgical appearance and contribute to the current literature.

\section{CASE PRESENTATION}

A 38-year old male patient presented with a 2week history of urinary incontinence and 1-month history of progressively worsening weakness in lower extremities. Examination of motor strength revealed bilateral disability in ankle and toe dorsiflexion. He had a saddle sensory loss and paresthesia below the L4 sensory level. He had a prior medical history of T-ALL, and he had been treated with allograft stem cell transplantation 5 years previously. The entire spinal contrast-enhanced magnetic resonance imaging (MRI) demonstrated an epidural mass lesion and significant spinal cord compression at the L2-L4 levels (Figure 1). There was no thickening in the dura mater. 

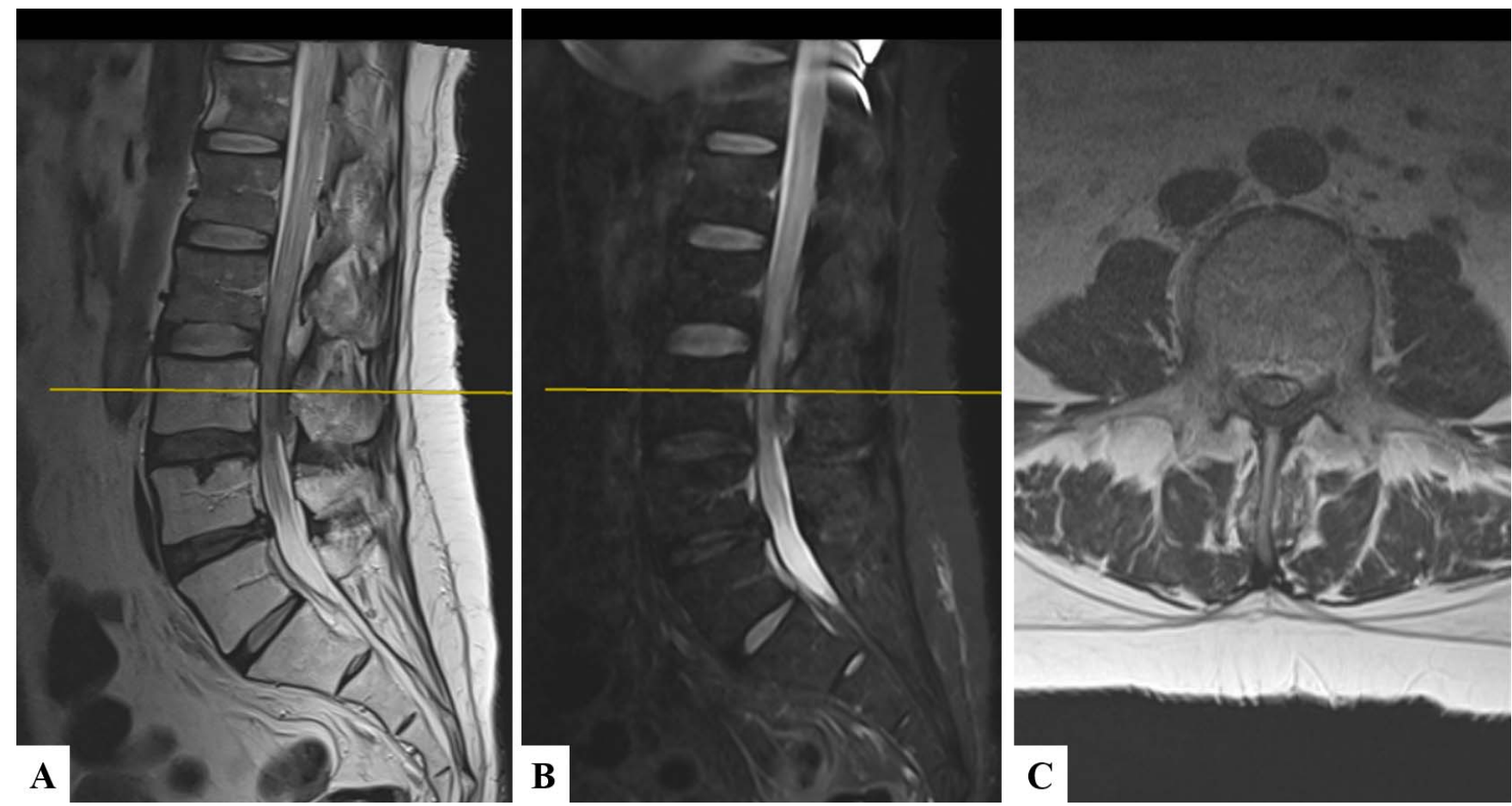

Figure 1. Preoperative (A) T2-weighted and (B) turbo inversion recovery lumbar spinal magnetic resonance imaging (MRI) showing the epidural lesion at L2-L4 levels in the sagittal plane. (C) T2-weighted MRI in axial plane showing spinal cord compression at the L3 level.

Leptomeningeal enhancement was not detected in the cranial MRI. The preoperative bone-marrow biopsy did not show involvement by the lymphoblasts. An 18F-fludeoxyglucose (18F-FDG) positron emission tomography scan of the chest, abdomen, and pelvis was performed and did not show any other mass lesion or any other pathological 18F-FDG involvement. The patient underwent surgery for tissue diagnosis. L3 total, and L2 and L4 bilateral partial decompressive laminectomies were performed. After removal of the ligamenta flava, the epidural mass lesion appeared (Figure 2). The tumor was adherent to dura mater and causing spinal stenosis. It was surrounding the spinal cord and extending from the recesses towards the left L3 neuroforamen. The posterior part of the tumor was excised. The biopsy consisted of yellow-colored, hypovascular, and soft tissue fragments of about 3.5 $\times 1.5 \times 0.3 \mathrm{~cm}$ (Figure 2). After 3 days from the surgery, the patient's lower extremity strength improved and he had an active movement in ankle dorsiflexion. The histopathological examination revealed the diagnosis of T-LBL (Figure 3). The patient underwent chemoradiotherapy for adjuvant treatment. At the 1-month follow-up, the bonemarrow biopsy was performed again, and lymphoblastic infiltration was detected. For his postallograft relapse, treatment with nelarabine and donor lymphocyte infusion started. At 2-month follow-up, there was no significant recovery in his urinary incontinence. After 5 months, the disease progressed, and the patient died because of infective endocarditis.

\section{DISCUSSION}

T-ALL and T-TBL are highly aggressive neoplasms of lymphoblasts. They are basically the same disease. The World Health Organization classification of lymphoid neoplasms has unified these entities as precursor T-cell lymphoblastic leukemia/lymphoma. T-LBL is considered to be leukemia when neoplastic cells are prominently circulating in the blood or blast cells infiltrates more than $25 \%$ of the bone marrow. In our case, the patient had a history of T-ALL (Figure 3), treated with allogeneic bone-marrow transplantation 5 years previously. When the motor weakness occurred and lumbar spinal stenosis was detected, the patient's blood did not contain blast cells and the bone marrow was not infiltrated by lymphoblasts. In the radiological imaging, there was no sign of any other mass lesion. Therefore, we operated our patient for tissue diagnosis. As the lumbar epidural tumor had lymphoblastic cell infiltration and the tumor displayed positivity with CD3 (Figure 3B) and TdT 

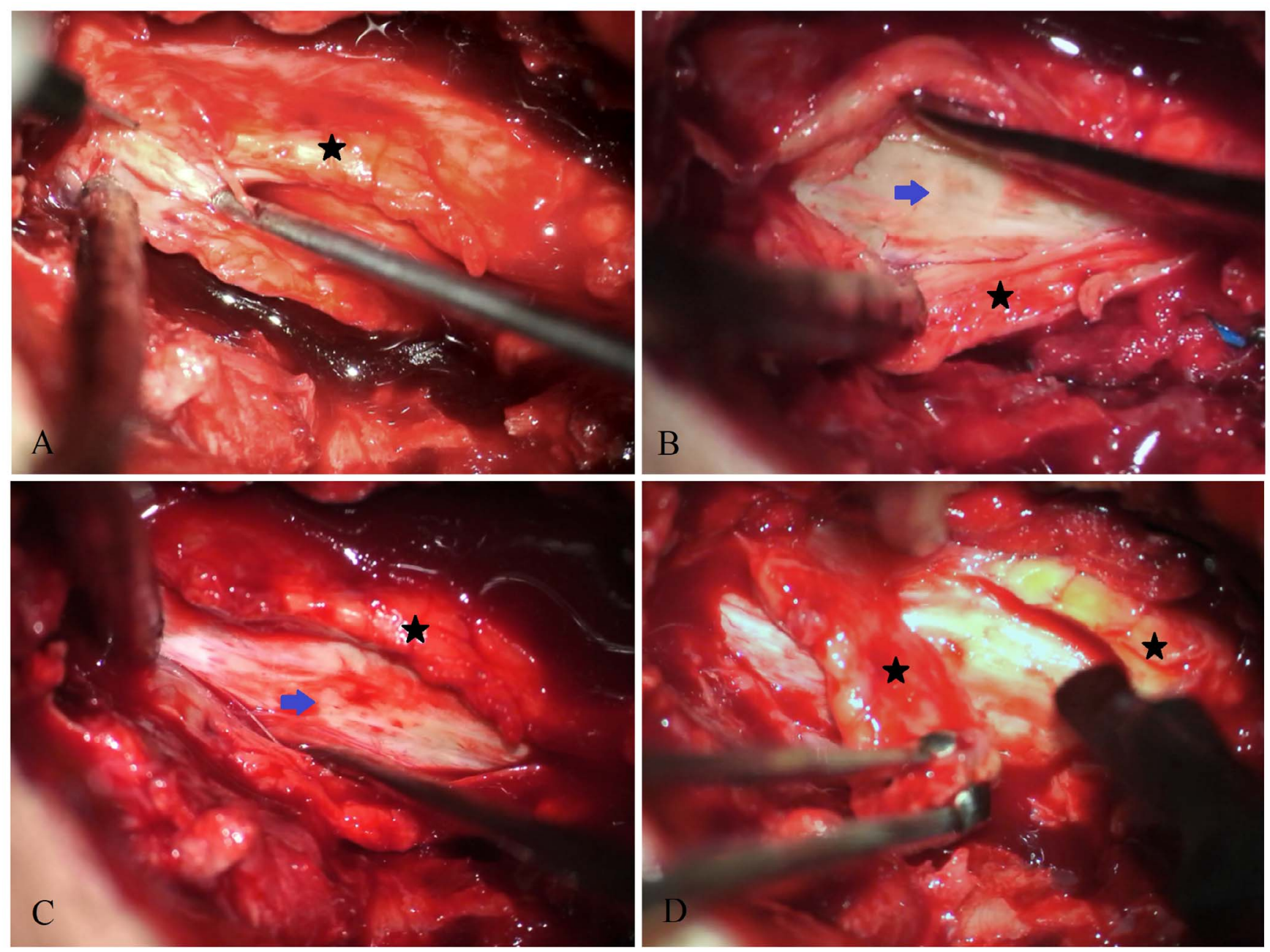

Figure 2. Intraoperative images showing the excision of posterior part of the tumor. (A) Yellow-colored tumor mass (black star) appearing after excision of ligamenta flava at the L3 level. (B) The tumor (black star) appearing to be adherent to the dura (blue arrow). (C) The posterior part of the tumor (black star) surrounding the dura. (D) The excision of the posterior part of the tumor (black star).

(Figure 3C), the diagnosis was determined as T-LBL.

Spinal epidural involvement has been reported in $0.8 \%-2.8 \%$ of all malignant lymphoma cases ${ }^{7}$ and is most commonly present in the thoracic spine, followed by the cervical spine and less commonly in the lumbar spine. ${ }^{8}$ These regions are may be the first site for a primary tumor, ${ }^{2,9}$ or may be the area for a metastasis ${ }^{10}$ while the disease is progressing. Acute paresis and/or incontinence require emergency decompression of the spinal cord. ${ }^{11}$ In patients without acute neurologic deficit or spinal instability, the treatment should be managed with primary radiotherapy and adjuvant chemotherapy ${ }^{12}$ because lymphomas are chemoradiosensitive tumors. In addition, decompressive laminectomy and subtotal resection have routinely been performed in patients with spinal instability or severe cord compression. ${ }^{13}$
As the tumor caused lumbar spinal stenosis and our patient had to be diagnosed histopathologically, we performed surgery. The patient underwent chemoradiotherapy after recurrent T-LBL was diagnosed.

Approximately $2 \%-5 \%$ of patients with nonHodgkin lymphoma have the complication of epidural spinal cord compression. ${ }^{10}$ The degree of spinal cord compression ranges from a minor asymptomatic indentation ${ }^{7}$ on the normal thecal sac contour to strangulation of the spinal cord ${ }^{14}$ with associated paraplegia. ${ }^{15}$ In our case, the location of the tumor around the spinal cord was remarkable. Because the tumor had surrounded the posterior and lateral borders of the spinal cord and reached its anterior border, the tumor caused spinal stenosis (Figure 1). The tumors generally spread through the path of least resistance and encircle the thecal sac. ${ }^{16}$ This characteristic appearance has been 

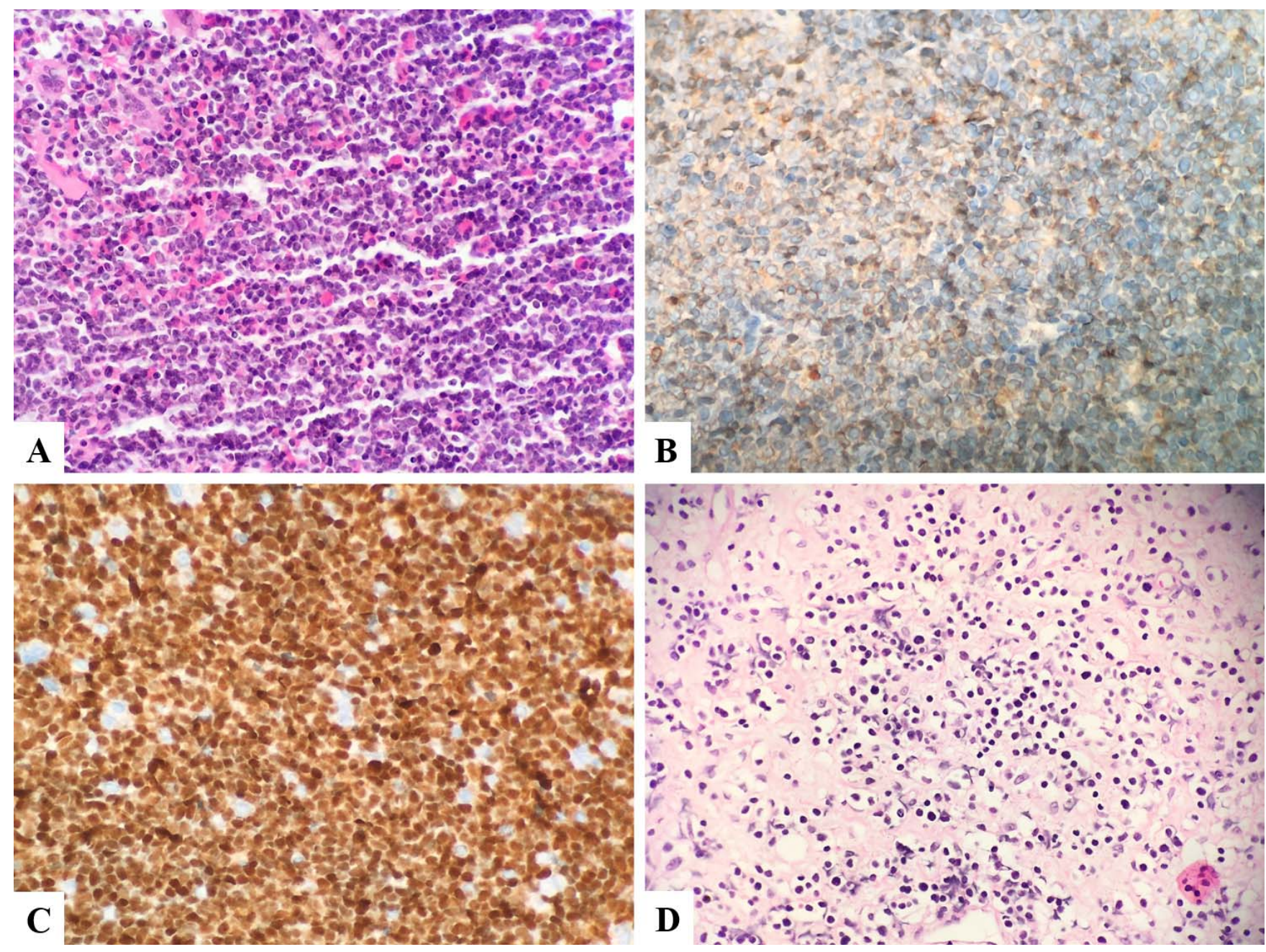

Figure 3. Histopathological examination showing (A) the primary tumor (T-cell acute lymphoblastic leukemia) with lymphoblastic cell infiltration in the bone-marrow biopsy (hematoxylin-eosin), (B) the primary tumor's positivity for cytoplasmic CD3 expression and (C) TdT. (D) The recurrent tumor with lymphoblastic cell infiltration in the lumbar epidural region (hematoxylin-eosin).

called "wrap-around." 17 Similarly, Patel et al ${ }^{14}$ reported an epidural non-Hodgkin lymphoma at the T2 level, with involvement of the posterior elements in a characteristic wrap-around fashion. In our case, the tumor had the same appearance, which was reaching out the lateral portion of epidural space and left L3 neural foramen (Figure 2).

\section{CONCLUSION}

In this report, we demonstrated microsurgical macroscopic appearance of spinal epidural T-LBL. Our aim was to indicate the probable presence of non-Hodgkin lymphomas in patients with epidural spinal cord compression and to contribute to the literature. In patients with long-term neurologic deficits, the gross total resection has no evidence for neurological improvement. The aim of the surgery should be tissue diagnosis, since the lymphomas are chemoradiosensitive tumors.

\section{REFERENCES}

1. Mally R, Sharma M, Khan S, Velho V. Primary lumbosacral spinal epidural non-Hodgkin's lymphoma: a case report and review of literature. Asian Spine J. 2011;5(3):192. doi:10. 4184/asj.2011.5.3.192

2. Wachter D, Tschischka S, Huegens-Penzel M, et al. T-cell lymphoma mimicking schwannoma of a cervical nerve root. Neurosurg Rev. 2009;32(1):117-121. doi:10.1007/s10143-0080169-x

3. Flouzat-Lachaniette C-H, Allain J, Roudot-Thoraval F, Poignard A. Treatment of spinal epidural compression due to hematological malignancies: a single institution's retrospective experience. Eur Spine J. 2013;22(3):548-555. doi:10.1007/ s00586-012-2562-y

4. The Non-Hodgkin's Lymphoma Classification Project. A clinical evaluation of the International Lymphoma Study Group classification of non-Hodgkin's lymphoma. Blood. 1997;89(11):3909-3918. 
5. Bassan R, Maino E, Cortelazzo S. Lymphoblastic lymphoma: an updated review on biology, diagnosis, and treatment. Eur J Haematol. 2016;96(5):447-460. doi:10.1111/ ejh.12722

6. Lepretre S, Graux C, Touzart A, Macintyre E, Boissel N. Adult T-type lymphoblastic lymphoma: treatment advances and prognostic indicators. Exp Hematol. 2017;51:7-16. doi:10. 1016/j.exphem.2017.04.002

7. Székely G, Miltényi Z, Mezey G, et al. Epidural malignant lymphomas of the spine: collected experiences with epidural malignant lymphomas of the spinal canal and their treatment. Spinal Cord. 2008;46(4):278-281. doi:10.1038/sj.sc.3102124

8. Kim DG, Nam DH, Jung HW, Choi KS, Han DH. Primary central nervous system lymphoma: variety of clinical manifestations and survival. Acta Neurochir (Wien). 1996;138(3):280-289. doi:10.1007/BF01411738

9. Nambiar RK, Nair SG, Prabhakaran PK, Mathew SP. Primary spinal epidural B-lymphoblastic lymphoma. Baylor Univ Med Cent Proc. 2017;30(1):66-68. doi:10.1080/08998280. 2017.11929533

10. Grier J, Batchelor T. Metastatic neurologic complications of non-Hodgkin's lymphoma. Curr Oncol Rep. 2005;7(1):55-60. doi:10.1007/s11912-005-0026-9

11. Córdoba-Mosqueda M, Guerra-Mora J, Sánchez-Silva M, Vicuña-González R, Torre A. Primary spinal epidural lymphoma as a cause of spontaneous spinal anterior syndrome: a case report and literature review. J Neurol Surg Reports. 2017;78(01):e1-e4. doi:10.1055/s-0036-1597692

12. Laufer I, Rubin DG, Lis E, et al. The NOMS framework: approach to the treatment of spinal metastatic tumors. Oncologist. 2013;18(6):744-751. doi:10.1634/theoncolo gist.2012-0293

13. Sobecks RM. Lymphoma. In: McLain, RF, Lewandrowski K, Markman M, Bukowski RM, Macklis R, Benzel EC, eds. Cancer in the Spine. Totowa, NJ: Humana Press; (2006):107-115. doi:10.1007/978-1-59259-971-4_14
14. Patel M, Wu OC, Kasliwal MK. Wrap-around appearance: underrecognized radiologic feature of spinal lymphoma. World Neurosurg. 2018;115:157-158. doi:10.1016/j. wneu.2018.04.051

15. Liu S-Z, Zhou X, Song A, Huo Z, Wang Y-P, Liu Y. Primary spinal epidural non-Hodgkin's lymphoma causing complete paralysis. QJM An Int J Med. 2018;111(11):813-814. doi:10.1093/qjmed/hcy151

16. Siegal T. Spinal cord compression: From laboratory to clinic. Eur J Cancer. 1995;31(11):1748-1753. doi:10.1016/09598049(95)00320-I

17. Pawha PS, Chokshi FH. Imaging of Spinal Manifestations of Hematological Disorders. Hematol Oncol Clin North Am. 2016;30(4):921-944. doi:10.1016/j.hoc.2016.03.011

Disclosures and COI: We did not receive any specific grant from funding agencies in the public, commercial, or not-for-profit sectors. The authors report no conflicts of interest.

Corresponding Author: Münibe Büşra Erdem, MD, Gazi University Faculty of Medicine, Department of Neurosurgery, Besevler, 06500, Ankara, Turkey. Phone: 0090536286 3335; Fax: 009031221290 04; Email: dr.mbusra@gmail.com.

Published 11 February 2021

This manuscript is generously published free of charge by ISASS, the International Society for the Advancement of Spine Surgery. Copyright (C 2020 ISASS. To see more or order reprints or permissions, see http://ijssurgery.com. 